DOI: https://doi.org/10.30749/2177-8337.v23n47p33-49

\title{
OS PRINCÍPIOS NORTEADORES DO PROCESSO CIVIL E SUA COMPATIBILIDADE COM A CRIAÇÃO E APLICABILIDADE DA TÉCNICA DE JULGAMENTO ESTENDIDO
}

\author{
THE GUIDING PRINCIPLES OF CIVIL PROCEEDINGS AND THEIR \\ COMPATIBILITY WITH THE CREATION AND APPLICATION OF THE \\ EXTENDED JUDGMENT TECHNIQUE
}

Maria Angélica de Oliveira Santos Alves*

Resumo: 0 presente artigo possui como objeto o estudo, utilizando pesquisas bibliográficas, da nova técnica de julgamento estendido prevista no artigo 942 do Código de Processo Civil de 2015 e sua compatibilidade com os princípios processuais. No tocante à estrutura, após a introdução, examina-se o papel da técnica de julgamento ampliado como substituta dos antigos embargos infringentes e por fim, apresenta-se a relação da técnica com os princípios processuais, que, com a tendência de constitucionalização do processo torna-se assunto indispensável para compreender os impactos do novo instituto.

Palavras-chave: Direito Processo Civil. Julgamento Estendido. Princípios processuais.

Abstract: The present article has as object the study, using bibliographic researches, of the new technique of extended judgment foreseen in article 942 of the Code of Civil Procedure of 2015 and his compatibility with the procedural principles. In the structure of the article, after the introduction, the extended judgment technique as a substitute for the old infringing embargoes is examined and, finally, the relation of the technique with the procedural principles is presented, which, with the tendency of constitutionalizing the process it becomes an indispensable subject to understand the impacts of the new institute.

Keywords: Civil Procedure Law. Extended Judgment. Procedural principles.

* Graduada em Direito pela Universidade Católica de Pernambuco (UNICAP). E-mail: mariaangelicadosa@gmail.com. 


\section{INTRODUÇÃO}

O sistema processual civil brasileiro sempre foi alvo de várias críticas, tendo como principal a alegação de que por ele não era apto para se alcançar a realização dos direitos reclamados, diante de uma demora exacerbada da resposta jurisdicional. Foi esse o contexto do Código de Processo Civil de 2015, onde inúmeras mudanças foram promovidas a fim de se atingir o que a muito era tido como seu principal defeito: a promoção de um processo célere, justo e que garantisse a segurança jurídica.

Nesse contexto, de necessária reforma processual, optou-se por suprimir os antigos embargos infringentes e em seu lugar criar uma nova técnica de ampliação do colegiado, que para fins didáticos será denominada no presente artigo de "julgamento estendido".

Para estudar tal assunto, o presente artigo, se usará da metodologia descritiva, analisando a criação da técnica de julgamento estendido e destacando sua relação com os princípios norteadores do processo civil.

Quanto às fontes utilizadas para a realização do presente estudo, fora feito um levantamento bibliográfico nas doutrinas mais relevantes a respeito do tema, bem como de jurisprudências importantes.

Em um primeiro momento, foi realizada uma exposição a respeito da transição do recurso de embargos infringentes à atual técnica de julgamento estendido, apresentando suas noções gerais.

Por fim, com a tendência de constitucionalização dos princípios processuais, foi necessário analisar de que maneira tais preceitos influenciaram na criação da técnica e de que forma o julgamento estendido mostra-se compatível a eles.

\section{A NOVA TÉCNICA DE JULGAMENTO ESTENDIDO COMO SUBSTITUTA DOS EMBARGOS INFRINGENTES}

O Código de Processo Civil de 1973 tratava os embargos infringentes como um recurso idôneo para combater acórdãos proferidos de forma não unânime em apelações e ações rescisórias, tendo sua aplicação expandida para apelações em mandado de segurança e em processo de falência. 
Os embargos infringentes durante toda sua vigência sofreram inúmeras contestações pelos doutrinadores e eram tidos como um recurso antiquado. Desde sua origem no direito lusitano, até a sua aplicação no texto jurídico nacional, os embargos infringentes foram sendo limitados com o tempo até sua extinção no atual Código de Processo Civil de 2015.

Os estudiosos de direito se dividiam quanto a função e aplicabilidade do instituto no âmbito nacional. Boa parte dos juristas interpretavam os embargos infringente como um excedente, levando em conta a disponibilidade recursal existente no direito pátrio e o entendimento cada vez mais pungente de que a celeridade processual deveria ser uma busca prioritária. Enquanto outros juristas advogavam pela positivação dos embargos infringentes como mais um meio de sanar possíveis vícios e injustiças presentes em decisões colegiadas, priorizado assim, a segurança jurídica.

Sobre sua aplicabilidade, Rodrigo da Cunha Lima Freire afirma que estatisticamente os embargos infringentes do CPC de 1973 nunca representaram um problema. Quanto a sua utilidade, porém, o instituto não se mostra vantajoso. Uma "apelação da apelação" ou uma "apelação da rescisória" serviria exclusivamente à quem sucumbiu, mas não ao sistema. "Se todos os julgamentos forem concluídos por votação não unânime, mas as turmas ou câmaras apresentarem um só entendimento a respeito da mesma matéria, estarão prestigiadas a segurança jurídica, a isonomia e a celeridade processual." (FREIRE, 2015).

Desde o início da elaboração do Anteprojeto do atual Código de Processo Civil, em 2010, especulavam os juristas sobre a presença dos embargos infringentes. Assim, na exposição de Motivos do Anteprojeto dizia o seguinte:

\footnotetext{
Uma das grandes alterações havidas no sistema recursal foi a supressão dos embargos infringentes. Há muito, doutrina da melhor qualidade vem propugnando pela necessidade de que sejam extintos. Em contrapartida a essa extinção, o relator terá o dever de declarar o voto vencido, sendo este considerado como parte integrante do acórdão, inclusive para fins de prequestionamento. (BRASIL, 2020).
}

Durante o processo legislativo que levou à criação do novo Código de Processo Civil, optou-se por uma postura intermediária, posto que, mesmo dando fim aos embargos infringentes, criou-se uma nova técnica para a continuidade do 
julgamento não unânime, visando com isso prestigiar a segurança jurídica, bem como promover a celeridade processual.

Dentre os objetivos do Novo Código de Processo Civil estava a facilitação dos procedimentos, abolindo formalidades ou atos dispensáveis, bem como a busca por uma maior efetividade, otimizando os resultados processuais. Assim, alguns institutos do processo civil, que iam de encontro à celeridade e eficiência, como alguns recursos, foram extintos ou mitigados - como no caso dos embargos infringentes.

A adoção da nova técnica de julgamento teve por finalidade o fornecimento de uma maior segurança jurídica e confiabilidade às questões divergentes, pois amplia o número de julgadores. O novo dispositivo "foi sensível ao fato de que a ausência de unanimidade pode constituir indício da necessidade de um maior aprofundamento da discussão a respeito da questão decidida, submeteu o resultado não unânime à ampliação do debate." (MARINONI; ARENHART; MITIDIERO, 2016, p. 886).

Em virtude dessas considerações José Maria Câmara Júnior dispõe:

\begin{abstract}
De toda sorte, o incidente de julgamento prolongado contribui para exaurir ou mitigar a divergência entre os julgadores que integram o mesmo órgão colegiado, consolidando a posição majoritária a partir de um procedimento simplificado, célere e automático. Como se vê, o artigo 942 não quer apenas permitir a inversão do resultado do julgamento não unânime, mas também pretende atingir uma maior homogeneidade de entendimento no órgão colegiado sobre determinada matéria, dissipando dúvidas e divergências internas, emprestando maior segurança jurídica e previsibilidade para o controle jurisdicional. Na verdade, sem alterar a gênese dos embargos infringentes, porquanto tanto o recurso que desaparece, quanto o incidente criado, possibilitam o reexame da matéria, decidida por maioria, e a consolidação de uma posição do órgão colegiado. Conclui-se, portanto, que a novidade está na imperatividade da regra, que assume caráter cogente para assegurar maior previsibilidade e segurança jurídica em relação ao controle jurisdicional desempenhado pelo órgão colegiado a partir da harmonização do resultado dos seus julgamentos. A técnica do artigo 942 quer acabar com a chamada "sorte da distribuição" e, com isso, assegura às partes o tratamento homogêneo do órgão colegiado para o julgamento da mesma tese jurídica. (CÂMARA JUNIOR, 2017, p. 83).
\end{abstract}

Portanto, a extensão do julgamento, assim, objetiva a criação de decisões mais completas e justas pelos tribunais, tendo em vista a possibilidade de nova discussão da matéria submetida a um quórum maior que possibilitará um julgamento 
mais estável, não sendo prejudicial a formalidade procedimental e acabando por evitar a procrastinação por meio de novos recursos.

\title{
3. DA COMPATIBILIDADE DOS PRINCÍPIOS PROCESSUAIS E A NOVA TÉCNICA DE JULGAMENTO ESTENDIDO
}

O Direito na atualidade se encontra num estado de constitucionalização, ou seja, sua adaptação visando um processo de adequação e integração à Constituição. Esse momento se dá como consequência do Neoconstitucionalismo, movimento que prevê a supremacia da Constituição e a necessidade de amoldamento das demais áreas do direito ao que é estabelecido na Lei Maior - que não será apenas um documento que dispõe metas, mas que busca sua efetividade. (SANTOS, 2016, p. $56)$.

Dalmo de Abreu Dallari afirma que:

\begin{abstract}
Uma das mais importantes inovações introduzidas pelo neoconstitucionalismo foi o reconhecimento da natureza jurídica dos princípios referidos expressamente ou implícitos no texto constitucional, igualando-os, em termos de eficácia e imediata exigibilidade, as normas constitucionais'; de modo que os princípios jurídicos constitucionais deixaram de ser tratados como "recomendações ou sugest6es" e passaram a ser "obrigat6rios e exigíveis por meios jurídicos. (DALLARI, 2010, p. 320321).
\end{abstract}

Conforme dispõe Eduardo Rodrigues dos Santos (2016, p. 66), nesse contexto, o direito processual, assim como os demais ramos do direito, tendo como marco a segunda metade do século $X X$, passou pelo momento de constitucionalização, fundamentando-se no paradigma do Estado Democrático de Direito e o humanismo ético.

Visa, portanto, deixar para trás o mero tecnicismo processual - fruto de um formalismo exacerbado, e exaltando o processo como direito-garantia, ou seja, como um instrumento assegurador da participação isonômica e efetiva de qualquer cidadão na fomentação da decisão jurisdicional.

De sorte que, tomando por base a Constituição Federal, após anos de debates nas Casas do Congresso Nacional, o Código de Processo Civil fora aprovado em 2015. Sendo ele elaborado com a finalidade de alcançar anseios tanto da população, quanto da comunidade jurídica. Buscou-se priorizar, para tanto, a 
ESTENDIDO

"isonomia nas decisões de casos similares e a efetividade, sem descurar das garantias processuais constitucionais, tendo como meta inafastável um resultado necessariamente justo." (CARNEIRO, 2016, p. 73).

Tendo como objetivos dispostos no anteprojeto do novo diploma processual:

1) estabelecer expressa e implicitamente verdadeira sintonia fina com a Constituição Federal; 2) criar condições para que o juiz possa proferir decisão de forma mais rente à realidade fática subjacente à causa; 3) simplificar, resolvendo problemas e reduzindo a complexidade de subsistemas, como, por exemplo, o recursal; 4) dar todo o rendimento possível a cada processo em si mesmo considerado; e, 5) finalmente, sendo talvez este último objetivo parcialmente alcançado pela realização daqueles mencionados antes, imprimir maior grau de organicidade ao sistema, dandoIhe, assim, mais coesão. (BRASIL, 2020).

Em decorrência dos objetivos traçados no Código de Processo Civil alterações no sistema e procedimento recursal foram feitas, tendo como uma de suas principais mudanças a extinção do recurso de embargo de instrumento, objeto de divergência doutrinária desde sua introdução no processo civil nacional. Porém, como já destacado anteriormente, a supressão desse recurso deu origem a criação da técnica de ampliação do colegiado - conhecida como julgamento estendido.

No sistema jurídico dos Estados Democráticos de Direito, prevalece uma estrutura voltada a norma, sendo ela dividida em dois tipos, quais sejam: regras e princípios. Dessa forma, consoante o Código de Processo Civil de 2015 tenha sido elaborado nesse sistema, o atual diploma processual consolidou inúmeros princípios e regras fundamentais, tratando das mesmas, principalmente, em seus artigos iniciais - consagrando, portanto, o modelo constitucional processual civil nacional.

São vários os princípios informadores do processo civil dispostos na Constituição Federal de 1988 e trazidos pelo atual Código de Processo Civil, como forma de entender a influência dos princípios processuais constitucionais, mas sem a intenção de esgotar o tema, será exposto os principais princípios que justificam a criação da técnica de julgamento estendido, substituta do antigo embargo infringente. 


\subsection{Do princípio democrático}

O processo judicial é uma forma sistemática de agir, indispensável ao exercício do poder de forma válida onde, ao fim, se espera que um juiz ou tribunal, com regular jurisdição, profira decisões sobre o direito acerca de uma pessoa ou propriedade.

Seu principal objetivo são a manutenção da integridade do ordenamento jurídico, a eliminação de litígios e a pacificação social. Para além disso, o processo funciona também como um meio de se alcançar a efetivação de direitos fundamentais constitucionalmente assegurados.

A Constituição da República Federativa do Brasil consolida em seu texto, fruto de um contexto sociopolítico pós golpe militar de 1964, um governo participativo o que rende ao texto da Lei Maior o título de "Constituição Cidadã", configurando um grande marco na história do país e consolidação de direitos e da própria democracia.

Neste contexto, o princípio da dignidade da pessoa humana, o pluralismo político e a cidadania se apresentam como fundamentos da República de acordo com a Constituição da República Federativa do Brasil, tendo a titularidade do poder o povo. Dessa forma, portanto, trata-se de norma de natureza estruturante da ordem jurídica, fundamental para a organização do poder, servido como orientador e limitador do exercício dele.

Em relação ao impacto do princípio democrático no caso da técnica de julgamento estendido poderia ser alegado que a ampliação do colegiado macula o princípio, tendo em vista que a votação poderia ter um fim por ter sido, apesar de não unânime, majoritária, o que não acontece com a aplicação da técnica.

Porém esse entendimento de afronta ao princípio democrático não deve prosperar, muito pelo contrário, tendo em vista que a ampliação do colegiado privilegia o princípio supracitado ao dispor que o julgamento não unânime seja ampliado de forma a fomentar o debate a respeito do tema, o que, em tese, acarretaria em um enriquecimento e qualificação da decisão judicial ao final do processo. 


\subsection{Do princípio da inafastabilidade do controle de jurisdição}

O princípio da inafastabilidade do controle de jurisdição encontra-se a norma em questão prevista no artigo 50, XXXV, da Constituição Federal de 1988: "a lei não excluirá da apreciação do Poder Judiciário lesão ou ameaça a direito".

Assim, tal princípio assegura a todos a possibilidade de acesso a justiça, quando o conflito não possa ser solucionado espontaneamente.

Trata-se de clara manifestação do Estado de Direito, que além de ser uma garantia de ingresso no Poder Judiciário de acordo com as pretensões e busca de reconhecimento e satisfação - protegendo direitos e garantias fundamentais, representa também uma garantia de outorga, a quem tiver razão, de uma tutela legal efetiva, adequada e tempestiva, bem como o impedimento de óbices ilegítimos à concessão da tutela eventualmente devida. (DINAMARCO; LOPES, 2017, p. 54).

$\mathrm{O}$ acesso à justiça é garantido pelo exercício do direito de ação, que permite ao interessado deduzir suas pretensões em juízo, para que sobre elas seja emitido um pronunciamento judicial. Esse direito sofre limitações que the são naturais e restringem sua amplitude, mas nem por isso constituem ofensa ao princípio da inafastabilidade do controle jurisdicional.

Por conseguinte, a técnica de julgamento estendido estimula o princípio da inafastabilidade do controle de jurisdição, já que a ampliação do colegiado possibilita que à parte obtenha uma nova análise de seu recurso (ou ação rescisória) em decorrência do julgamento não unânime sem necessidade de novo pagamento de custas processuais ou da assistência do advogado, sendo a aplicação da técnica automática.

Assim sendo, a técnica funciona, em tese, como uma potencializadora do direito de ação disposto como princípio constitucional, posto que tal princípio não só vislumbra assegurar um julgamento para as partes, mas um julgamento de qualidade, o que é um dos objetivos da ampliação do colegiado. 


\subsection{Do princípio do devido processo legal}

A Constituição da República Federativa do Brasil de 1988 consagra o princípio do devido processo legal em seu artigo 50, inciso LIV, da Constituição Federal, o qual prevê que "ninguém será privado da liberdade ou de seus bens sem o devido processo legal", também estando disposto no artigo $7^{\circ}$ do Código de Processo Civil de 2015.

Na visão de José Afonso da Silva (2005, p. 431-432), o princípio do devido processo legal em conjunto com o direito de acesso à justiça, o contraditório e a ampla defesa, integram um ciclo indispensável para a possibilidade de fomento de garantias processuais. Desta forma, é dado ao processo formas instrumentais adequadas que possibilitam a prestação jurisdicional, quando entregue pelo Estado, para que seja dado a cada um o que lhe é seu de direito.

A técnica de julgamento estendido funciona como manifestação, dentre outras garantias, do princípio do devido processo legal, não sendo, portanto, contrário a este. Porém, para garantir tal harmonia é necessário que os Regimentos Internos dos Tribunais que venham a regular a matéria atuem em conformidade com os preceitos constitucionais e processuais.

\subsection{Do princípio do contraditório e ampla defesa}

De acordo com o artigo 5, LX da Constituição Brasileira Federativa do Brasil "aos litigantes, em processo judicial ou administrativo, e aos acusados em geral são assegurados o contraditório e a ampla defesa, como os meios e recursos a ela inerentes". O assunto também encontra disposição no artigo 70 do Código de Processo Civil de 2015.

Pode-se extrair o conceito do princípio do contraditório da obra de Canuto Mendes de Almeida (1973, p. 82), o qual determina que se trata de uma ciência bilateral dos atos e termos que envolvem o processo, dando a possibilidade de contrariá-los, representando uma garantia dada às partes para que elas participem de forma efetiva da formação do convencimento do juiz. Encontrando amparo no devido processo legal. 
Em sentido amplo, o contraditório relaciona-se com os atos praticados durante o processo, sendo resultado da participação ativa das partes. Conforme dispõe Edilson Mougenot Bonfim:

Relevante é que o juiz, antes de proferir cada decisão, ouça as partes, dando-lhes igual oportunidade para que se manifestem, apresentando argumentos e contra-argumentos. Destarte, o juiz, ao proferir a decisão, deve oferecer às partes oportunidade para que busquem, pela via da argumentação, ou juntando elementos de prova, se for o caso, influenciar a formação de sua convicção. (BONFIM, 2015, p. 91).

Diante do que fora apontado acima é notório que a bilateralidade da ação gera a bilateralidade do processo. Dessa forma, no processo haverá ao menos duas figuras que serão denominadas de partes: o autor e o réu. $O$ autor instaurará a ação, mas a relação só será completa com o chamado do réu a juízo, dando a possibilidade de apresentação do contraditório, visto que somente pelo conjunto da parcialidade das partes é que o juiz poderá formar seu convencimento.

O princípio da ampla defesa, disposto conjuntamente com o princípio do contraditório no artigo 5, LV do texto constitucional, funciona como complemento daquele. Posto que, de forma efetiva, não seria possível uma relação processual sem o chamamento do réu para integrar o processo, não faria sentido se o mesmo não pudesse se apresentar para defesa de seu interesse.

Dessa forma, de acordo com o princípio da ampla defesa, é garantido que ninguém poderá sofrer os efeitos de uma sentença sem ter tido a possibilidade de ser parte do processo do qual está provém, sendo indispensável, portanto, a efetiva possibilidade de participação na formação da decisão judicial.

Com relação à incidência dos princípios mencionados acima na técnica de julgamento estendido, o contraditório é a justificativa utilizada para possibilitar a nova sustentação oral em caso de ampliação do colegiado, com o intuito de tornar a questão o mais clara possível, em especial em relação aos novos julgadores.

Em casos onde o julgamento for designado para outra sessão, o contraditório permitirá às partes a apresentação de memoriais sobre a matéria objeto de divergência, dando ensejo a um debate mais hábil para aperfeiçoamento de uma nova decisão. 


\subsection{Do princípio da motivação das decisões}

A fundamentação das decisões trata-se de uma exigência intransponível determinada pela Constituição Federal de 1988, conhecida como princípio da motivação e disposta no artigo 93, IX, da Lei Maior e no artigo 11, do Código de Processo Civil de 2015, ligando-se tanto aos preceitos de justiça e confiabilidade, tanto à concepção de cidadania e democracia.

Tendo em vista que o Estado Democrático de Direito caracteriza-se por ser o "Estado que se justifica", o poder se auto limita a regras procedimentais específicas, sendo portanto a liberdade de convencimento do juiz limitada a uma motivação que objetiva promover transparência no exercício do poder pelo juiz, também do conhecimento pelas partes e o controle pelos órgãos superiores da Magistratura, bem como o controle feito pela opinião pública (DINAMARCO; LOPES, 2017, p. 72).

$\mathrm{Na}$ visão de Lenio Streck a fundamentação possui relação íntima com o princípio do contraditório, tendo papel de destaque no Estado Democrático de Direito, vez que deságua na "garantia que cada cidadão tem de que a decisão estará devidamente fundamentada e respeitará a dialética processual desenvolvida pelas partes." (STRECK, 2009, p. 17-18).

Sendo a ausência da motivação fundamento para nulidade da decisão, conforme dispõe a Constituição Federal da República em seu artigo 93, II e o Código de Processo Civil no artigo 11.

Como visto, a motivação das decisões judiciais é elemento indispensável num Estado de Direito, sendo importante destacar que o que se almeja é a busca de uma motivação material e não formal, ou seja, materialmente falando a motivação consiste em um raciocínio idôneo com a finalidade de demonstrar que o alegado poderá ter sua veracidade aferida por meio de provas produzidas no processo.

Muitas vezes o que se constata na prática é a aplicação da motivação meramente formal, esvaziada de análise técnica precisa e decorrente da fase probatória, o que ocorre, por exemplo, em casos onde se replicam termos do dispositivo legal ou se utilizam de fórmulas genéricas utilizadas para inúmeros casos, muitas vezes diferentes em sua essência.

Nesse sentido ensina Paulo Henrique dos Santos Lucon: 
A colegialidade faz parte da essência de um tribunal. Infelizmente, a realidade vem mostrando que em muitos casos ocorre um monólogo em certas turmas julgadoras e impera o julgamento monocrático. É uma realidade brasileira, que tem origem variada, mas principalmente na enorme quantidade de processos (100 milhões!). Julgamentos em massa, julgamentos automáticos vêm a colaborar com uma sensível perda da colegialidade. Quem participou de um colegiado sabe o que se está a falar. Com tal instituto, que é sim uma criação brasileira (e não há qualquer demérito nisso!) e se justifica pelas particularidades que temos, a divergência passa a ser uma atitude mais consciente, muito mais responsável, e permite, sem a menor dúvida, que o tribunal chegue a julgamentos dotados de infinita e superior qualidade. (LUCON, 2015).

Em se tratando da técnica de julgamento estendido a ampliação da colegialidade tem como um de seus fundamentos o enriquecimento do princípio da motivação das decisões judiciais, tendo em vista que tal instituto alarga o debate dos pontos objetos de divergência, fomentando assim uma discussão mais rica e completa.

\subsection{Do princípio do juiz natural}

A garantia do juiz natural versa sobre a obrigatoriedade de os atos praticados no exercício da função estatal jurisdição sejam realizados por juízes instituídos pela própria Constituição e competentes segundo a lei, sendo proibido o juízo extraordinário ou tribunal de exceção - aquele constituído posterior ao fato.

A Constituição da República Federativa do Brasil de 1988 trata do princípio do juiz natural no artigo 50, incisos XXXVII, LIII e LIV.

Tal princípio configura-se, portanto, como um mandamento jurídico de densidade axiológica que consolida várias garantias em seu conteúdo. Assim, o princípio não deve ser reduzido como mero instrumento proibitivo de tribunais de exceção, visto se tratar de uma garantia complexa que dá origem a novos subprincípios indispensáveis para o Estado Democrático de Direito, possibilitando a garantia de preceitos fundamentais, com a dignidade, a liberdade e a ampla defesa. (SILVA, 2005, p. 117).

Conforme dispõe Marcelo Navarro Ribeiro Dantas (2013, p. 734) o fato de os julgadores serem de origem de Turma ou Câmara diversa poderia corromper 0 
princípio do juiz natural. Entendimento diverso é exposto por Fredie Didier Junior e Leonardo da Cunha (2016, p. 78), que discorrem que a definição adiantada, que funciona como um dos critérios objetivos para convocação dos novos julgadores que iram ampliar o colegiado está de acordo com tal princípio.

Diante da análise do princípio do juiz natural e de todo o exposto acima, adota-se no presente artigo o entendimento de que não há de se falar em mácula da garantia constitucional do juiz natural, posto que a essência do princípio é a promoção de um juiz imparcial e competente.

Como já abordado anteriormente, havendo julgamento não unânime haverá, de acordo com o artigo 942 do Código de Processo Civil, a interrupção do julgamento e serão convocados novos julgadores. Caberá ao regulamento interno do tribunal como será convocado esses novos integrantes.

Nesse contexto, o regimento interno deve estabelecer critérios prévios e objetivos para a convocação dos julgadores que irão integrar a ampliação do colegiado. É indispensável a determinação prévia para se atender o princípio do juiz natural e para a observância do contraditório.

Como exposto, o juiz competente para julgar os processos dirigidos ao Tribunal são os integrantes dos órgãos fracionários, órgãos este que não deve ser confundido com os juízes que o compõem, sendo a convocação dos julgadores determinada pelo regimento interno dos Tribunais de forma anterior ao julgamento portanto não há de se falar em juízo de exceção.

\subsection{Do princípio da celeridade processual e da segurança jurídica}

A Emenda Constitucional n. 45/2004 incluiu no rol das garantias constitucionais do processo o princípio da celeridade processual. A celeridade caracteriza-se por dois aspectos principais: a razoabilidade na duração do processo e a celeridade em sua tramitação.

A análise feita no presente artigo não ignora o mérito da corrida contra o tempo travada no processo, mas, o trabalho em pauta tem o cuidado de destacar que o processo, de forma paradoxal, carece de tempo, tendo em vista o aumento da complexidade. Necessitando, portanto, de mais argumentos e debates. 
Nelson Nery Júnior (2009, p. 314) argumenta que a celeridade desempenha também a função de promover os meios alternativos de solução de conflitos, como mecanismo idôneo a ensejar a redução da carga de demanda na justiça ordinária, reduzindo, assim, a duração do processo de maneira geral.

Podemos, diante das noções abordadas anteriormente, delimitar três critérios que devem ser analisados para se aferir qual é a duração razoável de um processo: a complexidade da causa; o comportamento dos litigantes; e forma de atuação do órgão do poder judiciário. (ZARIF, 2006, p. 144).

Assim, é completamente compreensível que causas que englobam maior complexidade, que demandam provas periciais mais completas tenham um tempo maior para a obtenção do provimento jurisdicional.

Dessa forma, não basta se preocupar unicamente com a solução do mérito, é necessário que essa solução seja alcançada em um tempo razoável, evitando-se procrastinações que vão de encontro a garantia do pleno acesso à justiça, conforme dispõe a Constituição Federal em seu artigo 50, LXXVIII.

O autor também destaca que é necessário, para se determinar o que seria uma duração razoável, que se atendessem alguns critérios de análise, como por exemplo a natureza do processo e sua complexidade, a atuação das partes e de seus procuradores, a colaboração de atos administrativos para a elucidação do caso, dentre outros. (NERY JUNIOR, 2009, p. 315).

Apesar do julgamento estendido apresentar questionamentos em relação a sua compatibilidade com a celeridade processual, não se deve analisar a questão unilateralmente, o que se busca no processo judicial não é apenas uma decisão rápida, mas uma decisão que atenda a justiça de forma efetiva, consagrando ao final a satisfação não só da parte, mais também da sociedade.

Apesar da alegação que dispõe que a ampliação do colegiado poderia atrasar o andamento processual, segundo entendimento de Paulo Henrique dos Santos Lucon (2015) todos que tem experiência no foro têm consciência de que o atraso processual decorre do chamado "tempo de prateleira", sendo está física ou virtual, tratando-se no lapso temporal que o processo permanece inerte.

Sendo, por assim dizer, uma verdadeira paralisia processual decorrente de inúmeras fontes, dentre elas a má estruturação estatal. Por conseguinte, o tempo 
investido na ampliação do colegiado não representaria grade espera diante do tempo total do processo.

O Poder Judiciário tem como uma de suas missões atender a celeridade processual, consagrada como garantia fundamental e ideal a ser alcançado pelo Estado Democrático de Direito, ao mesmo tempo que protege a segurança jurídica na tomada de suas decisões, promovendo a efetividade das normas processuais e enfatizando o papel da justiça perante a sociedade.

Nesse sentido, o princípio da celeridade fundamentou a supressão do recurso de embargos infringentes e sua substituição pelo uso da técnica de julgamento estendido, que de um lado garante a parte o direito de fazer prevalecer o voto vencido, com a ampliação do quórum de votação, e, do outro, acelera o processo, eliminando um recurso.

Criando-se, portanto, uma técnica de julgamento com o objetivo de simplificar o procedimento, não havendo necessidade de recorrer, nem prazo para contrarrazões. Assim, havendo divergência o processo continuará de forma automática, de uma maneira mais barata e célere, se distanciando de formalidades exacerbadas que acabam por prejudicar a duração razoável do processo.

Conclui-se, portanto, que tomando a celeridade como um meio e não como um fim, a técnica de julgamento estendido reúne a segurança jurídica e a celeridade nos processos, mas, para que seja alcançada sua plena efetividade, há necessidade de uma adequação do regimento interno dos tribunais para que estejam em conformidade com os atuais objetivos traçados pelo Novo Código de Processo Civil.

\section{CONCLUSÃO}

Esse artigo possibilitou compreender a trajetória que permeou a criação da técnica de julgamento estendido pelo Código de Processo Civil de 2015 em supressão aos antigos embargos infringentes. Com isso, pode-se perceber a necessidade de esclarecimento a respeito da influência que os princípios constitucionais causaram na nova técnica, bem como o seu papel para garantir preceitos constitucionais.

Foi possível concluir que a substituição dos embargos infringentes pela nova técnica de julgamento estendido consagrou vários objetivos do anteprojeto do atual 
diploma processual, quais sejam: uma sintonia com a Constituição Federal, possibilidade de decisões mais próximas da realidade, imprimindo, por fim, um maior grau de organicidade ao sistema, dando-lhe mais coesão. Notória se faz a consagração dos princípios processuais abordados no presente estudo por meio da aplicação da ampliação do colegiado.

\section{REFERÊNCIAS}

ALMEIDA. Joaquim Canuto Mendes de. Princípios fundamentais do processo penal. São Paulo: Revista dos Tribunais, 1973.

BONFIM, Edilson Mougenot. Curso de processo penal. 10. ed. São Paulo: Saraiva, 2015.

BRASIL. Exposição de motivos do código de processo civil: Lei no 13.105, de 16 de março de 2015. In: ABREU FILHO, Nylson Paim de (org.). VADE mecum: interativo. Porto Alegre: Verbo Jurídico, 2020. Disponível em:

http://www.verbojuridico.com.br/vademecum/CPC_EXPOSICAO_DE_MOTIVOS.pdf. Acesso em: 20 ago. 2019.

CÂMARA JUNIOR, José Maria. Técnica de colegialidade do artigo 942 do CPC: extensão e profundidade da matéria submetida ao julgamento prolongado. In: NERY JUNIOR, Nelson; ALVIM, Teresa Arruda. Aspectos polêmicos dos recursos cíveis e assuntos afins. São Paulo: Revista dos Tribunais, 2017. No prelo.

CARNEIRO, Paulo Cezar Pinheiro. Das normas fundamentais do processo civil. In: WAMBIER, Teresa Arruda Alvim; DIDIER JUNIOR, Fredie; TALAMINI, Eduardo; DANTAS, Bruno. Breves comentários ao novo código de processo civil. 2. ed. São Paulo: Revista dos Tribunais, 2016. p. 57-104.

DALLARI, Dalmo de Abreu. A constituição na vida dos povos: da Idade Média ao século XXI. São Paulo: Saraiva, 2010.

DINAMARCO, Cândido; LOPES, Bruno. Teoria geral do novo processo civil. 2. ed. São Paulo: Malheiros, 2017.

DANTAS, Marcelo Navarro Ribeiro. A problemática dos embargos infringentes no projeto do novo código de processo civil. Salvador: JusPODIVM, 2013.

DIDIER JUNIOR, Fredie; CUNHA, Leonardo Carneiro da. Curso de direito processual civil: meios de impugnação às decisões judiciais e processo nos tribunais. 13. ed. Salvador: JusPODIVM, 2016. 
FREIRE, Rodrigo da Cunha Lima. A técnica da complementação do julgamento da apelação no novo CPC. [S. I.], 2015. Disponível em: http://portalprocessual.com/a-tecnica-da-complementacao-do-julgamento-daapelacao-no-novo- cpc/. Acesso em: 21 jul. 2019.

LUCON, Paulo Henrique dos Santos. Técnica criada no novo CPC permite decisões com mais qualidade. Consultor Jurídico, [S. I.], p. 1-8, 2015. Disponível em: http://www.conjur.com.br/2015-fev-04/paulo-lucon-cpc-permite-decisoesqualidade\#_ftn5. Acesso em: 03 jul. 2019.

MARINONI, Luiz Guilherme; ARENHART, Sérgio Cruz; MITIDIERO, Daniel. Novo código de processo civil comentado. 2. ed. São Paulo: Revista dos Tribunais, 2016.

NERY JUNIOR, Nelson. Princípios do processo na constituição federal. 9. ed. São Paulo: Revista dos Tribunais, 2009.

SANTOS. Eduardo Rodrigues. Princípios processuais constitucionais. Salvador: JusPODIVM, 2016.

SILVA, José Afonso da. Curso de direito constitucional positivo. 25. ed. São Paulo: Malheiros, 2005.

STRECK, Lenio Luiz. Hermenêutica, constituição e processo. Belo Horizonte: Del Rey, 2009.

ZARIF, Cláudio Cintra. Da necessidade de repensar o processo para que ele seja realmente efetivo. In: FUX, Luiz; NERY JUNIOR, Nelson; WAMBIER, Teresa Arruda Alvim. Processo e constituição: estudos em homenagem ao Professor José Carlos Barbosa Moreira. São Paulo: Revista dos Tribunais, 2006. p. 139-145.

Recebido em 22/03/2020.

Aceito em 07/04/2020. 